\title{
MDM2 and P53 polymorphisms contribute together to the risk and survival of prostate cancer
}

\author{
Li Xue ${ }^{1, *}$, Xiujuan Han ${ }^{2, *}$, Rongrong Liu ${ }^{3}$, Ziming Wang ${ }^{1}$, Hecheng Li ${ }^{1}$, Qi Chen ${ }^{1}$, \\ Peng Zhang ${ }^{1}$, Zhenlong Wang ${ }^{1}$ and Tie Chong ${ }^{1}$ \\ ${ }^{1}$ Department of Urology, The Second Affiliated Hospital, Xi'an Jiaotong University, Xian, China \\ 2 The Helmholtz Sino-German Research Laboratory for Cancer, Department of Pathology, Tangdu Hospital, The Fourth Military \\ Medical University, Xian, China \\ ${ }^{3}$ Department of Pathology, School of Basic Medicine, Fourth Military Medical University, Xian, Shaanxi, China \\ * These authors have contributed equally to this work \\ Correspondence to: Tie Chong, email: chongtiexian@126.com
}

Keywords: MDM2 gene; p53 gene; prostate cancer; risk; survival

Received: March 11, $2015 \quad$ Accepted: April 08, 2015

Published: May 18, 2015

This is an open-access article distributed under the terms of the Creative Commons Attribution License, which permits unrestricted use, distribution, and reproduction in any medium, provided the original author and source are credited.

\section{ABSTRACT}

The p53 gene and MDM2 gene play critical roles in cell cycle arrest and apoptosis together. Here, we evaluated the associations of prostate cancer risk and survival with the joint effects of $\mathrm{mdm} 2$ and p53 polymorphisms. Totally 1,193 cases and 1,310 age frequency-matched controls were included in the study. Prostate cancer patients were followed to determine the intervals of overall survival and disease-free survival. The Pro ${ }^{72} \mathrm{Arg}$ Pro allele (homozygous and heterozygous) were significantly associated with prostate cancer risk with an odds ratio (OR) of 0.77 [95\% confidence interval (CI), 0.64-0.93]. SNP309 $\mathrm{T}$ alleles were associated with a significantly decreased prostate cancer risk among Pro ${ }^{72}$ Arg Pro alleles carriers (OR=0.79, 95\% CI, 0.640.98). In addition, compared with the Pro ${ }^{72}$ Arg Pro alleles and SNP309 G homozygous, patients carrying both SNP309 $\mathrm{T}$ alleles and Pro ${ }^{72}$ Arg Arg homozygous had more favorable disease-free survival (hazard ratio $[H R]=0.59,95 \% \mathrm{CI}, 0.38-0.93$ ). Our results indicated that SNP309 and Pro ${ }^{72}$ Arg polymorphisms may jointly contribute to the etiology and prognosis of prostate cancer.

\section{INTRODUCTION}

Prostate cancer is the second most frequently diagnosed cancer and the sixth leading cause of cancerrelated death among males worldwide [1]. It is the most common type of cancer in men in the United States, with 186,000 new cases in 2008 and 28,600 deaths [2]. It has been recognized that prostate cancer, which is a complex and multifactorial disease, is a result of interplay between different exposures and host susceptibility. The tumor suppressor p53 pathway could prevent carcinogenesis by causing cell cycle arrest or apoptosis [3-5]. The p53 gene has a functional single nucleotide polymorphism (SNP), the $\mathrm{G}>\mathrm{C}$ change at codon72 in exon 4 (Pro72Arg, rs 1042522), which results in an arginine-to-proline change in the protein sequence [6]. This polymorphism is located in the proline-rich domain which is necessary for the P53 protein to fully induce apoptosis [7]. The Arg allele is significantly more efficient in inducing apoptosis, while the Pro allele appears to have a higher capacity for DNA repair and cell cycle G1 arrest [8]. It's also reported that the polymorphism of TP53 at codon 72 could influence the accumulation of mtDNA mutations [9]. Human mouse double-minute 2 protein gene ( $\mathrm{mdm} 2$ ) is an important negative regulator of p53 and its over expression is associated with increased metastasis, decreased response to therapy, and poor prognosis [10-13]. A functional SNP in the mdm2 gene promoter region (SNP309, rs2279744) elevated $\mathrm{mdm} 2$ gene transcription under the influence of estrogens signaling and the subsequent attenuation of the p53 pathway and may represent a cancer predisposing allele $[14,15]$.

Given the functional relevance of $\mathrm{p} 53$ and $\mathrm{mdm} 2$ in cell-cycle control and apoptosis, the combination of these polymorphisms is expected to determine susceptibility and prognosis of the prostate cancer more accurately than 
Table 1: Clinical characteristics of the controls and patients

\begin{tabular}{|c|l|l|l|}
\hline Variables & Patients $(\mathbf{n}=\mathbf{1 , 1 9 3})$ & Controls $(\mathbf{n}=\mathbf{1 , 3 1 0})$ & $\boldsymbol{P}$-value \\
\hline Age at diagnosis & $69.5 \pm 8$ & $70.1 \pm 9$ & 0.08 \\
\hline Family history & & & \\
\hline Yes & 154 & 30 & \\
\hline No & 1,039 & 1,280 & $P<0.001$ \\
\hline Smoking status & & & \\
\hline Never & 915 & 1,041 & 0.091 \\
\hline Ever & 278 & 269 & \\
\hline Drinking status & & & 0.411 \\
\hline Never & 892 & 998 & \\
\hline Ever & 301 & 312 & \\
\hline Body mass index & & & 0.654 \\
\hline$<25 \mathrm{~kg} / \mathrm{m}^{2}$ & 656 & 721 & \\
\hline $25-29.9 \mathrm{~kg} / \mathrm{m}^{2}$ & 477 & 537 & \\
\hline$\geq 30 \mathrm{~kg} / \mathrm{m}^{2}$ & 60 & 52 & \\
\hline PSA levels at diagnosis, ng/mL & $20.7 \pm 6.6$ & & \\
\hline Gleason score & & & \\
\hline $2-6$ & 620 & & \\
\hline 7 & 418 & & \\
\hline $8-10$ & 155 & & \\
\hline Clinical stage, T3\% & $67(5.6 \%)$ & & \\
\hline Treatment & & & \\
\hline hormonal therapy & 675 & & \\
\hline Androgen Deprivation & 251 & & \\
\hline Radiation & 489 & & \\
\hline
\end{tabular}

alone. We hypothesized that common variants of mdm2 and p53 and their joint effects are associated with risk and survival of prostate cancer. We therefore performed genotyping analyses for SNPs of SNP309, SNP354 in $\mathrm{mdm} 2$ gene and $\mathrm{Pro}^{72} \mathrm{Arg}$ in p53 gene in a large casecontrol study conducted in Chinese male population.

\section{RESULTS}

The clinical features of the 1,193 patients with prostate cancer and 1,310 control males are shown in Table 1. The mean age of the prostate cancer patients and the controls at the time that the blood was drawn was 69.5 and 70.1 years, respectively. There were no significant differences between the controls and cases with regard to age, smoking status, drinking status or BMI.

Table 2 shows the association between SNP309 and SNP354 in mdm2 and Pro ${ }^{72}$ Arg in p53 gene and prostate cancer risk. The distribution of genotypes for these three polymorphisms is consistent with the Hardy-Weinberg equilibrium for both cases and controls. Compared with subjects with the $\mathrm{Pro}^{72} \mathrm{Arg} / \mathrm{Arg}$ homozygous, those with the Pro $^{72} A r g$ Pro allele, including the homozygous and heterozygous categories, had showed a protective effect on prostate cancer (odds ratio $[\mathrm{OR}]=0.77,95 \%$ confidence interval [CI], 0.64-0.93, $\left.P=5.54 \times 10^{-3}\right)$. Stratified analyses by Gleason score and clinical stage showed that no significant difference (supplementary table 1).

In order to evaluate the joint effect of $\mathrm{mdm} 2$ polymorphisms and $\mathrm{p} 53 \mathrm{Arg}^{72}$ Pro genotypes on prostate cancer risk, we performed stratification analyses by p 53 $\mathrm{Arg}^{72}$ Pro genotypes. As shown in Table 3, we found that the variant genotypes of SNP309 GT and TT were associated with a significantly decreased prostate cancer risk among carriers with p53 Pro alleles $(\mathrm{OR}=0.79,95 \%$ CI: 0.64-0.98, P for interaction $=0.0112$ ). We examined the potential interactive effect between SNP354 and p53 $\mathrm{Pro}^{72} \mathrm{Arg}$ genotypes and no significant interaction were observed.

The median follow-up time for prostate cancer patients was approximately 7 years. Table 4 presents HRs and $95 \%$ CIs of mdm 2 and $\mathrm{p} 53$ polymorphisms after adjustment for potential confounding factors, including TNM stage, radiotherapy, and age. Overall, neither overall survival nor disease-free survival was associated with the SNP309, SNP354 or Pro $^{72}$ Arg polymorphisms (Table 4). We next addressed whether there is a joint effect of $\mathrm{mdm} 2$ and p53 polymorphisms on prostate cancer survival. We found a statistically significant interaction between SNP309 and $\mathrm{Pro}^{72} \mathrm{Arg}$ for prostate cancer diseasefree survival $\left(P_{\text {interaction }}=0.0298\right)$. Compared with the Pro $^{72} \mathrm{Arg}$ Pro alleles (homozygous and heterozygous) and SNP309 G homozygous, patients carrying both SNP309 $\mathrm{T}$ (homozygous and heterozygous) and $\mathrm{Pro}^{72} \mathrm{Arg}$ Arg 
Table 2: MDM2 and p53 genotypes and prostate cancer risk

\begin{tabular}{|l|c|c|c|}
\hline Genotype & Cases & Controls & Adjusted OR (95\% CI)* \\
\hline MDM2 & & & \\
\hline SNP309 & & & 1.00 (reference) \\
\hline GG & 334 & 356 & $1.00(0.83-1.21)$ \\
\hline GT & 565 & 602 & $0.89(0.71-1.12)$ \\
\hline TT & 227 & 272 & $0.97(0.81-1.15)$ \\
\hline GT+TT & 792 & 874 & 1.00 (reference) \\
\hline SNP354 & & & $1.15(0.73-1.83)$ \\
\hline AA & 1037 & 1046 & \\
\hline AG & 40 & 35 & 1.00 (reference) \\
\hline P53 & & & $0.77(0.64-0.93)$ \\
\hline P53 codon72 & & & 305 \\
\hline Arg/Arg & 339 & 875 & \\
\hline Arg/Pro or Pro/Pro & 751 & & \\
\hline
\end{tabular}

* Asjusting for age at diagnosis, family history, smoking status, dringk status, and BMI

Table 3: Gene-gene interaction of MDM2 and p53 genotypes for prostate cancer risk

\begin{tabular}{|c|c|c|c|c|c|c|}
\hline \multirow[t]{3}{*}{ Genotypes } & \multicolumn{6}{|c|}{ p53 codon 72} \\
\hline & \multicolumn{3}{|c|}{ Arg/Arg } & \multicolumn{3}{|c|}{$\mathrm{CG}+\mathrm{CC}$} \\
\hline & Case & Control & $\mathrm{OR}(95 \% \mathrm{CI})^{*}$ & Case & Control & $\mathrm{OR}(95 \% \mathrm{CI}) *$ \\
\hline \multicolumn{7}{|l|}{ MDM2 SNP 309} \\
\hline GG & 80 & 91 & 1.00 (reference) & 244 & 232 & 1.00 (reference) \\
\hline \multirow[t]{2}{*}{$\mathrm{GT}+\mathrm{TT}$} & 256 & 207 & $1.41(0.99-1.99)$ & 502 & 604 & $0.79(0.64-0.98)$ \\
\hline & \multicolumn{6}{|c|}{$p$ for interaction $=\mathbf{0 . 0 1 1 2}$} \\
\hline \multicolumn{7}{|l|}{ MDM2 SNP 354} \\
\hline AA & 308 & 285 & 1.00 (reference) & 687 & 706 & 1.00 (reference) \\
\hline $\mathrm{AG}$ & 13 & 10 & $1.20(0.52-2.79)$ & 27 & 24 & $1.16(0.66-2.02)$ \\
\hline & \multicolumn{6}{|c|}{$p$ for interaction $=0.9406$} \\
\hline
\end{tabular}

* Adjusting for age at diagnosis, family history, smoking status, dringk status, and BMI

Table 4: Association of mdm2 and p53 genotypes and prostate cancer survival.

\begin{tabular}{|c|c|c|c|c|c|}
\hline \multirow{2}{*}{ Genotypes } & \multirow{2}{*}{ Case } & \multicolumn{2}{|c|}{ Overall survival } & \multicolumn{2}{|c|}{ Disease-free survival } \\
\hline & & Events & $\operatorname{HR}(95 \% \mathrm{CI}) *$ & Events & $\operatorname{HR}(95 \% \mathrm{CI}) *$ \\
\hline \multicolumn{6}{|c|}{ mdm2 } \\
\hline \multicolumn{6}{|l|}{ SNP309 } \\
\hline GG & 334 & 74 & 1.00 (reference) & 97 & 1.00 (reference) \\
\hline $\mathrm{GT}+\mathrm{TT}$ & 792 & 169 & $1.03(0.78-1.35)$ & 210 & $0.93(0.73-1.19)$ \\
\hline GT & 565 & 120 & $1.01(0.75-1.36)$ & 148 & $0.92(0.71-1.19)$ \\
\hline TT & 227 & 49 & $1.06(0.73-1.52)$ & 62 & $0.97(0.71-1.35)$ \\
\hline \multicolumn{6}{|l|}{ SNP354 } \\
\hline $\mathrm{AA}$ & 1037 & 220 & 1.00 (reference) & 281 & 1.00 (reference) \\
\hline $\mathrm{AG}$ & 40 & 11 & $1.20(0.65-2.22)$ & 11 & $1.07(0.58-1.95)$ \\
\hline \multicolumn{6}{|c|}{ P53 } \\
\hline \multicolumn{6}{|l|}{ SNP codon 72} \\
\hline Arg/Arg & 339 & 72 & 1.00 (reference) & 97 & 1.00 (reference) \\
\hline Arg/Pro or Pro/Pro & 522 & 107 & $1.06(0.78-1.43)$ & 132 & $0.96(0.74-1.26)$ \\
\hline
\end{tabular}

* Adjusting for age at diagnosis, family history, PSA levels at diagnosis, PSA recurrence, Gleason score, clinical stage, and treatment. 
Table 5: Gene-gene interaction of $\mathrm{mdm} 2$ and p53 genotypes in relation to the prostate cancer survival.

\begin{tabular}{|c|c|c|c|c|c|c|c|c|c|c|c|c|}
\hline \multirow{4}{*}{ Genotypes } & \multicolumn{6}{|c|}{ Overall survival } & \multicolumn{6}{|c|}{ Disease-free survival } \\
\hline & \multicolumn{6}{|c|}{ P53 codon72 } & \multicolumn{6}{|c|}{ P53 codon72 } \\
\hline & \multicolumn{3}{|c|}{ Arg/Arg } & \multicolumn{3}{|c|}{ Arg/Pro or Pro/Pro } & \multicolumn{3}{|c|}{ Arg/Arg } & \multicolumn{3}{|c|}{ Arg/Pro or Pro/Pro } \\
\hline & Case & Events & $\begin{array}{l}\mathrm{HR}(95 \% \\
\mathrm{CI})^{*}\end{array}$ & Case & Events & $\begin{array}{l}\mathrm{HR} \quad(95 \% \\
\mathrm{CI})^{*}\end{array}$ & Case & Events & $\begin{array}{l}\mathrm{HR}(95 \% \\
\mathrm{CI})^{*}\end{array}$ & Case & Events & $\begin{array}{l}\mathrm{HR} \quad(95 \% \\
\mathrm{CI})^{*}\end{array}$ \\
\hline \multicolumn{13}{|l|}{$\begin{array}{l}m d m 2 \\
S N P 309\end{array}$} \\
\hline GG & 80 & 21 & $\begin{array}{l}1.00 \\
\text { (reference) }\end{array}$ & 244 & 51 & $\begin{array}{l}1.00 \\
\text { (reference) }\end{array}$ & 80 & 30 & $\begin{array}{l}1.00 \\
\text { (reference) }\end{array}$ & 244 & 66 & \begin{tabular}{|l|}
1.00 \\
(reference)
\end{tabular} \\
\hline \multirow[t]{2}{*}{$\mathrm{GT}+\mathrm{TT}$} & 256 & 51 & $\begin{array}{l}0.71(0.41- \\
1.21) \\
\end{array}$ & 502 & 109 & $\begin{array}{l}1.18(0.84- \\
1.66) \\
\end{array}$ & 256 & 66 & $\begin{array}{l}0.59(0.38- \\
0.93) \\
\end{array}$ & 502 & 134 & $\begin{array}{l}1.08(0.80- \\
1.46)\end{array}$ \\
\hline & \multicolumn{6}{|c|}{$p$ for interaction $=0.1353$} & \multicolumn{6}{|c|}{$p$ for interaction $=0.0298$} \\
\hline \multicolumn{13}{|l|}{$\begin{array}{l}m d m 2 \\
\text { SNP } 354\end{array}$} \\
\hline AA & 308 & 64 & $\begin{array}{l}1.00 \\
\text { (reference) }\end{array}$ & 687 & 145 & $\begin{array}{l}1.00 \\
\text { (reference) }\end{array}$ & 308 & 89 & \begin{tabular}{|l}
1.00 \\
(reference)
\end{tabular} & 687 & 181 & $\begin{array}{l}1.00 \\
\text { (reference) }\end{array}$ \\
\hline AG & 13 & 4 & $\begin{array}{l}1.37(0.48- \\
3.90)\end{array}$ & 27 & 7 & $\begin{array}{l}1.20(0.56- \\
2.58)\end{array}$ & 13 & 4 & $\begin{array}{l}1.38(0.50- \\
3.85)\end{array}$ & 27 & 7 & $\begin{array}{l}0.97(0.45- \\
2.07)\end{array}$ \\
\hline & \multicolumn{6}{|c|}{$p$ for interaction $=0.8222$} & \multicolumn{6}{|c|}{$p$ for interaction $=0.5864$} \\
\hline
\end{tabular}

* Adjusting for age at diagnosis, family history, PSA levels at diagnosis, PSA recurrence, Gleason score, clinical stage, and treatment.

homozygous had more favorable disease-free survival [hazard ratio $(\mathrm{HR})=0.59,95 \%$ CI: $0.38-0.93$ ]. These sup-group patients also had better overall survival rates, although the association was not statistically significant $(\mathrm{HR}=0.71,95 \%$ CI: 0.41-1.21). However, we did not find the same strong relationship between SNP354 and Pro $^{72}$ Arg polymorphisms (Table 5).

\section{DISCUSSION}

In the present study we examined whether genetic polymorphisms in p53 and mdm2, alone or in combination, are associated with the risk and survival of prostate cancer in a Chinese population. Our results demonstrate that $\mathrm{Pro}^{72} \mathrm{Arg}$ Pro alleles were significantly associated with decreasing prostate cancer risk. A joint protective effect of $\mathrm{Pro}^{72} \mathrm{Arg}$ Arg alleles and SNP309 T alleles were detected. Furthermore, we found a significant gene-gene interaction between SNP309 and $\mathrm{Arg}^{72}$ Pro variants in relation to survival of prostate cancer.

The $\mathrm{Arg}^{72}$ Pro polymorphism in p53 gene was well characterized in both functional analyses and association studies [16-21]. Our data suggested that the Pro alleles were potent genetic protective factor for prostate cancer. The findings are supported by the earlier described functional significance of the $\mathrm{Pro}^{72} \mathrm{Arg}$ polymorphism and studies for association of $\mathrm{Pro}^{72} \mathrm{Arg}$ Pro with prostate cancer risk [22-25]. We did not find SNP309 or SNP354 polymorphism alone to be associated with prostate cancer risk. In consistent, null association between SNP309 and prostate cancer were also observed in other population [26]. No study has examined the joint effect of polymorphisms in $\mathrm{mdm} 2$ and p53 genes in prostate cancer risk. Interestingly, we found a significant joint protective effect of $\mathrm{Pro}^{72} \mathrm{Arg} / \mathrm{Pro}$ alleles and SNP309 T alleles in Chinese population. The joint effect between these two genotypes is biologically plausible. MDM2 and P53 act in the same causal pathway for carcinogenesis $[27,28]$. MDM2 down regulates P53 activity by binding it directly and forming the MDM2-P53 complex, which results in ubiquitination and proteasome degradation of P53 through the E3 ubiquitin ligase activity of MDM2 [29]. If a cell carries functional polymorphisms in both genes that diminish the expression of MDM2 and heighten the function of P53, a gene-gene joint protective effect would be expected [29]. It has been shown that the Pro $^{72} \mathrm{Arg}$ Pro allele (homozygous and heterozygous) was positively associated with the transcriptional activity of p53 gene in vitro [8]. The SNP309 G homozygous result in overexpression of MDM2 protein and thus inhibits chromatin-bound P53 from activating the transcription of its target genes $[14,30]$. In this regard, one may expect that individuals with the Pro ${ }^{72} \mathrm{Arg}$ Pro alleles (homozygous and heterozygous) and SNP309 $\mathrm{T}$ alleles (homozygous and heterozygous) are less susceptible to cancer.

Another intriguing observation evident from this study is that patients carrying both SNP309 $\mathrm{T}$ alleles (homozygous and heterozygous) and $\mathrm{Pro}^{72} \mathrm{Arg}$ Arg homozygous had more favorable disease-free survival. This result is supported by an in vitro study, which showed that after treatment with etoposide to induce DNA damage, which activates the p53 pathway, significant death was observed in cells with the SNP309 T homozygous but not in cells with the SNP309 G homozygous [14]. Moreover, $\mathrm{Pro}^{72} \mathrm{Arg}$ Arg allele have been shown to induce apoptosis more efficiently than Pro allele, which may also accelerate 
the apoptosis of tumor cell [4, 31-33]. Therefore, the coexistence of SNP309 $\mathrm{T}$ alleles (homozygous and heterozygous) and Pro $^{72} \mathrm{Arg}$ Arg homozygous is expected to be associated with a favor prognosis. In addition to altering tumor development, the Pro ${ }^{72} \mathrm{Arg}$ polymorphism may alter the sensitivity of tumors to chemotherapeutic agents, Pro ${ }^{72} \mathrm{Arg}$ Arg homozygous might be predicted to respond more favorably to radiation or chemotherapy.

Strengths of this study include the population-based study design and a high response rate, which minimized potential selection bias. The detailed exposure information collected in the study enabled an evaluation of gene-gene interactions. Information on cancer characteristics and treatment was obtained from the vast majority of patients, allowing an evaluation of possible effect modifications. There are also a few limitations that must be considered in evaluating these results. As mentioned above, the small sample size used for some of the stratified analyses is a limitation, resulting in unstable risk estimates and insufficient statistical power for interaction tests.

In summary, our results provide evidence that the p53 Pro $^{72} \mathrm{Arg}$ Pro allele was a protective factor for prostate cancer. Pro ${ }^{72}$ Arg Pro allele plus SNP309 T allele were associated with a decreased prostate cancer risk. In addition, SNP309 T allele and Pro ${ }^{72}$ Arg Arg allele had a joint effect of favor disease-free survival in prostate cancer patients, and the association with survival seemed to be independent from other clinical prognostic factors such as cancer stage.

\section{MATERIALS AND METHODS}

\section{Study population}

The study protocol was approved by committees of relevant institutes for the use of human subjects in research. All participants gave written informed consent. All the data of our study were stored in publicly available resources of The Second Affiliated Hospital of Xi'an Jiaotong University and available for related researchers by request. Totally this study included 1,459 men (age ranged from 39 to 87) and diagnosed with prostate cancer through a rapid case-ascertainment system using specimens from prostatic needle biopsies from Tangdu hospital, Xijing hospital and the Second Affiliated Hospital of Xi'an Jiaotong University,. A histopathological diagnosis was made by an experienced pathologist. The histological grading of the biopsy specimens was performed using Gleason's system by the same pathologist.

Meanwhile, 1,556 controls were identified and frequency matched to the expected age distribution of cases by 5-year age groups. A structured questionnaire was used to elicit detailed information on demographic factors.
Blood samples were collected from 1,193 (82\%) cases and $1,310(84 \%)$ controls and used in this study for genotyping assays. Prostate cancer patients were followed for cancer recurrence and mortality by using a combination of two active follow-up surveys and record linkage to the registry of death certificates.

\section{Genotyping and quality control}

Genotyping for SNP309 (rs2279744), SNP354 (rs769412) and Pro ${ }^{72}$ Arg (rs1042522) was performed using the Affymetrix MegAllele Targeted Genotyping System (Affymetrix, Santa Clara, CA) according to the Affymetrix's protocol. Blinded $(n=39)$ and HapMap samples $(n=12)$ were also included with the genotyping, consistency rates averaged $99.6 \%$. The consistence rate for the quality control samples was $99.88 \%$.

\section{Statistical analyses}

All statistical analyses were conducted with SAS version 9.2 (SAS Institute Inc.). All statistical tests were 2-tailed, and $P<0.05$ was interpreted as statistically significant unless otherwise indicated. Multivariable logistic regression was used to estimate odds ratios (OR) and $95 \%$ confidence intervals $(95 \% \mathrm{CI})$ for risk of prostate cancer, while adjusting for the confounders including age at diagnosis, family history, smoking status, drink status, and BMI. The Cox proportional hazard models were applied to evaluate hazard ratios (HRs) for the association of mdm 2 and p53 polymorphisms with the overall survival (OS) and disease-free survival (DFS), adjusting for age at diagnosis, family history, PSA levels at diagnosis, PSA recurrence, Gleason score, clinical stage, and treatment.

\section{Abbreviations}

CI, confidence interval; DFS, disease-free survival; $\mathrm{HR}$, hazard ratio; OR, odds ratio; OS, overall survival; SNP, single nucleotide polymorphism

\section{ACKNOWLEDGEMENTS}

This study was supported by the Fundamental Research Funds for the Central Universities and the National Natural Science Foundation of China (NSFC 81200552 to L.X.).

\section{CONFLICTS OF INTEREST}

The authors have no conflicts of interest to disclose. 


\section{REFERENCES}

1. Jemal A, Bray F, Center MM, Ferlay J, Ward E and Forman D. Global cancer statistics. CA Cancer J Clin. 2011; 61:6990 .

2. Jemal A, Siegel R, Ward E, Hao Y, Xu J, Murray T and Thun MJ. Cancer statistics, 2008. CA Cancer J Clin. 2008; 58:71-96.

3. Levine AJ. p53, the cellular gatekeeper for growth and division. Cell. 1997; 88:323-331.

4. Soussi T and Beroud C. Assessing TP53 status in human tumours to evaluate clinical outcome. Nat Rev Cancer. 2001; 1:233-240.

5. Blagosklonny MV. Tumor suppression by $\mathrm{p} 53$ without apoptosis and senescence: conundrum or rapalog-like gerosuppression? Aging (Albany, NY). 2012; 4:450-455. doi: 10.18632/aging.100475.

6. Thomas M, Kalita A, Labrecque S, Pim D, Banks L and Matlashewski G. Two polymorphic variants of wild-type p53 differ biochemically and biologically. Mol Cell Biol. 1999; 19:1092-1100.

7. Baptiste N, Friedlander P, Chen X and Prives C. The proline-rich domain of $\mathrm{p} 53$ is required for cooperation with anti-neoplastic agents to promote apoptosis of tumor cells. Oncogene. 2002; 21:9-21.

8. Pim D and Banks L. p53 polymorphic variants at codon 72 exert different effects on cell cycle progression. Int J Cancer. 2004; 108:196-199.

9. Altilia S, Santoro A, Malagoli D, Lanzarini C, Ballesteros Alvarez JA, Galazzo G, Porter DC, Crocco P, Rose G, Passarino G, Roninson IB, Franceschi C and Salvioli S. TP53 codon 72 polymorphism affects accumulation of mtDNA damage in human cells. Aging (Albany, NY). 2012; 4:28-39. doi:10.18632/aging.100425.

10. Hernandez I, Maddison LA, Wei Y, DeMayo F, Petras T, Li B, Gingrich JR, Rosen JM and Greenberg NM. Prostatespecific expression of $\mathrm{p} 53$ (R172L) differentially regulates p21, Bax, and mdm2 to inhibit prostate cancer progression and prolong survival. Mol Cancer Res. 2003; 1:1036-1047.

11. Zhang Z, Li M, Wang H, Agrawal S and Zhang R. Antisense therapy targeting MDM2 oncogene in prostate cancer: Effects on proliferation, apoptosis, multiple gene expression, and chemotherapy. Proc Natl Acad Sci U S A. 2003; 100:11636-11641.

12. Wang H, Yu D, Agrawal S and Zhang R. Experimental therapy of human prostate cancer by inhibiting MDM2 expression with novel mixed-backbone antisense oligonucleotides: in vitro and in vivo activities and mechanisms. Prostate. 2003; 54:194-205.

13. Leite KR, Franco MF, Srougi M, Nesrallah LJ, Nesrallah A, Bevilacqua RG, Darini E, Carvalho CM, Meirelles MI, Santana I and Camara-Lopes LH. Abnormal expression of MDM2 in prostate carcinoma. Mod Pathol. 2001; 14:428-
436.

14. Bond GL, Hu W, Bond EE, Robins H, Lutzker SG, Arva NC, Bargonetti J, Bartel F, Taubert H, Wuerl P, Onel K, Yip L, Hwang SJ, Strong LC, Lozano G and Levine AJ. A single nucleotide polymorphism in the MDM2 promoter attenuates the p53 tumor suppressor pathway and accelerates tumor formation in humans. Cell. 2004; 119:591-602.

15. Bond GL, Hirshfield KM, Kirchhoff T, Alexe G, Bond EE, Robins H, Bartel F, Taubert H, Wuerl P, Hait W, Toppmeyer D, Offit K and Levine AJ. MDM2 SNP309 accelerates tumor formation in a gender-specific and hormone-dependent manner. Cancer Res. 2006; 66:51045110

16. Zhang L, Shao N, Yu Q, Hua L, Mi Y and Feng N. Association between p53 Pro72Arg polymorphism and prostate cancer risk: a meta-analysis. Journal of biomedical research. 2011; 25:25-32.

17. Zhu Y, Wang J, He Q and Zhang JQ. Association of p53 codon 72 polymorphism with prostate cancer: a metaanalysis. Mol Biol Rep. 2011; 38:1603-1607.

18. Ricks-Santi L, Mason T, Apprey V, Ahaghotu C, McLauchlin A, Josey D, Bonney G and Dunston GM. p53 Pro72Arg polymorphism and prostate cancer in men of African descent. Prostate. 2010; 70:1739-1745.

19. Jung-Hynes B and Ahmad N. Role of p53 in the antiproliferative effects of Sirt1 inhibition in prostate cancer cells. Cell Cycle. 2009; 8:1478-1483.

20. Zhou Z, Flesken-Nikitin A, Corney DC, Wang W, Goodrich DW, Roy-Burman P and Nikitin AY. Synergy of p53 and $\mathrm{Rb}$ deficiency in a conditional mouse model for metastatic prostate cancer. Cancer Res. 2006; 66:7889-7898.

21. Quinones LA, Irarrazabal CE, Rojas CR, Orellana CE, Acevedo C, Huidobro C, Varela NE and Caceres DD. Joint effect among p53, CYP1A1, GSTM1 polymorphism combinations and smoking on prostate cancer risk: an exploratory genotype-environment interaction study. Asian J Androl. 2006; 8:349-355.

22. Michopoulou V, Derdas SP, Symvoulakis E, Mourmouras N, Nomikos A, Delakas D, Sourvinos G and Spandidos DA. Detection of human papillomavirus (HPV) DNA prevalence and p53 codon 72 (Arg72Pro) polymorphism in prostate cancer in a Greek group of patients. Tumour Biol. 2014; 35:12765-12773.

23. Lu Y, Liu Y, Zeng J, He Y, Peng Q, Deng Y, Wang J, Xie L, Li T, Qin X and Li S. Association of p53 codon 72 polymorphism with prostate cancer: an update metaanalysis. Tumour Biol. 2014; 35:3997-4005.

24. Mi YY, Zhu LJ, You XM and Wu S. Clarification of data for a meta-analysis: p53 codon 72 polymorphism and prostate cancer risk. Genetics and molecular research : GMR. 2012; 11:1958-1959.

25. Rogler A, Rogenhofer M, Borchardt A, Lunz JC, Knoell A, Hofstaedter F, Tannapfel A, Wieland W, Hartmann A 
and Stoehr R. P53 codon 72 (Arg72Pro) polymorphism and prostate cancer risk: association between disease onset and proline genotype. Pathobiology. 2011; 78:193-200.

26. Chen T, Yi SH, Liu XY and Liu ZG. Meta-analysis of associations between the MDM2-T309G polymorphism and prostate cancer risk. Asian Pac J Cancer Prev. 2012; 13:4327-4330.

27. Knappskog $\mathrm{S}$ and Lonning PE. Effects of the MDM2 promoter SNP285 and SNP309 on Sp1 transcription factor binding and cancer risk. Transcription. 2011; 2(5):207-210.

28. Knappskog S and Lonning PE. MDM2 promoter SNP285 and SNP309; phylogeny and impact on cancer risk. Oncotarget. 2011; 2:251-258.

29. Oliner JD, Pietenpol JA, Thiagalingam S, Gyuris J, Kinzler KW and Vogelstein B. Oncoprotein MDM2 conceals the activation domain of tumour suppressor p53. Nature. 1993; 362:857-860.

30. Arva NC, Gopen TR, Talbott KE, Campbell LE, Chicas A, White DE, Bond GL, Levine AJ and Bargonetti J. A chromatin-associated and transcriptionally inactive p53Mdm2 complex occurs in mdm2 SNP309 homozygous cells. J Biol Chem. 2005; 280:26776-26787.
31. Suspitsin EN, Buslov KG, Grigoriev MY, Ishutkina JG, Ulibina JM, Gorodinskaya VM, Pozharisski KM, Berstein LM, Hanson KP, Togo AV and Imyanitov EN. Evidence against involvement of $\mathrm{p} 53$ polymorphism in breast cancer predisposition. Int J Cancer. 2003; 103:431-433.

32. Toyama T, Zhang Z, Nishio M, Hamaguchi M, Kondo N, Iwase $\mathrm{H}$, Iwata $\mathrm{H}$, Takahashi $\mathrm{S}$, Yamashita $\mathrm{H}$ and Fujii Y. Association of TP53 codon 72 polymorphism and the outcome of adjuvant therapy in breast cancer patients. Breast Cancer Res. 2007; 9:R34.

33. Vannini I, Zoli W, Tesei A, Rosetti M, Sansone P, Storci G, Passardi A, Massa I, Ricci M, Gusolfino D, Fabbri F, Ulivi P, Brigliadori G, Amadori D and Bonafe M. Role of p53 codon 72 arginine allele in cell survival in vitro and in the clinical outcome of patients with advanced breast cancer. Tumour Biol. 2008; 29:145-151. 